\title{
ARQUITECTURA NEOCLÁSICA EN CÁDIZ: TORCUATO CAYÓN Y TORCUATO BENJUMEDA
}

TEODORO FALCÓN MÁRQUEZ | UNIVERSIDAD DE SEVILLA

ORCID iD: 0000-0002-1300-708X

\begin{abstract}
RESUMEN
En este artículo se analiza la evolución de la arquitectura en la ciudad de Cádiz y su zona de influencia, en la segunda mitad del siglo XVIII y primer tercio del XIX, cuando tuvo lugar la culminación de la arquitectura barroca y el desarrollo de la neoclásica. En este proceso desempeñaron un papel importante los ingenieros militares, la influencia de la Academia de San Fernando de Madrid, arquitectos que trabajaban en la Corte y el establecimiento en Cádiz de arquitectos foráneos, que contribuyeron a difundir el nuevo estilo. En esa evolución fue decisiva la intervención del arquitecto Torcuato Cayón y su discípulo Torcuato Benjumeda, el máximo representante del neoclasicismo en esta zona.
\end{abstract}

PALABRAS CLAVE

Arquitectura neoclásica, Cádiz, Torcuato Cayón, Torcuato Benjumeda.

This article analyzes the evolution of architecture in the city of Cadiz and its area of influence, in the second half of the 18th century and the culmination of the first of the 19th century, when the culmination of the Baroque and the development of Neoclassicism took place. Military engineers, the influence of the San Fernando Academy in Madrid and the architects who worked at the Court, played an important role in this process. The establishment in Cadiz of foreign architects who introduced the new style also had an influence. In this evolution, the role played by Torcuato Cayón and his disciple Torcuato Benjumeda, the highest representative of neoclassicism in this area, was decisive.

\section{KEYWORDS}

Neoclassic architecture, Cadiz, Torcuato Cayón, Torcuato Benjumeda. 


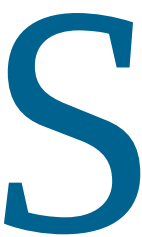

i desde 1717 el puerto de Cádiz tuvo el monopolio del comercio americano, en detrimento del de Sevilla, pese a los sucesivos decretos de libertad de comercio que se promulgaron a partir de 1765, la economía gaditana no quedó perjudicada, sino que siguió en aumento. García-Baquero sostiene que entre 1778-88 las exportaciones de esta ciudad experimentaron un incremento del 420\%. La población, asimismo, aumentó un 85,25\% con relación a la de primeros del siglo XVIII. Este hecho incidió en la arquitectura y urbanismo de la ciudad, que agotó entonces el espacio del istmo, creciendo verticalmente, edificándose casas de 4 o 5 plantas, fenómeno que no tuvo parangón con el resto de las ciudades andaluzas. La tendencia alcista del comercio alcanzó su punto culminante en torno a 1792. Con relación a 1778 supuso un incremento del 512\% ${ }^{1}$. En la década de 1770 Cádiz fue una de las pocas ciudades españolas que tenía infraestructuras sanitarias. De esta pulcritud vendría el epíteto de "Tacita de Plata". Las primeras ordenanzas del espacio urbano se llevaron a cabo en 1765. Por iniciativa del regidor Francisco Huarte se dividió la ciudad en cinco cuarteles o barrios. Es por tanto esta ordenación anterior a la realizada en Sevilla por Pablo de Olavide en 1771. La siguiente división de Cádiz tuvo lugar en 1792, con 17 barrios. El municipio veló en todo momento para que el crecimiento en vertical de la ciudad no se llevara a cabo de forma anárquica. En 1746 ya se establece una altura máxima de 17 varas, poco más de 14 metros. La política municipal gaditana del siglo XVIII llegó a su culmen con las Ordenanzas de 1792, que responden a las disposiciones de la Real Órden de 25 de noviembre de $1777^{2}$. Estas ordenanzas tuvieron gran trascendencia, ya que en virtud de ellas va a desaparecer oficialmente la arquitectura barroca y se va a dar el respaldo definitivo a la estética neoclásica. Con ellas se van a prohibir uno de los elementos más representativos del paisaje urbano de la ciudad, las torres miradores, porque se estimaba que sobrecargaban los edificios, y por temor de desplome en caso de terremotos. El aspecto que ofrecía la ciudad en esa época tan boyante, cuando se edificaron los edificios más representativos, se ofrece en la maqueta realizada por el ingeniero Alfonso

\footnotetext{
1 GARCÍA-BAQUERO GONZÁLEZ, Antonio. Comercio colonial y guerras revolucionarias. La decadencia económica de Cádiza raíz de la emancipación americana. Sevilla: Escuela de Estudios Hispanoamericanos, 1972. Ibidem. Comercio y burguesía mercantil en el Cádiz de la Carrera de Indias. Cádiz: Diputación, 1991. Ibidem. Cádiz y el Atlántico (1717-1778). Cádiz: Diputación, 1998. PÉREZ SERRANO, Julio. La población de Cádiz a fines del Antiguo Régimen (su estructura $\gamma$ mecanismos de renovación (1775-1800). Cádiz: Ayuntamiento, 1989. BARRIENTOS GARCÍA, María del Mar. Cádiz, su puerto y su bahía. La aplicación de leyes de libre comercio. En Trocadero, 2010, pp.21-22.

2 GUILLÉN TATO, J. Índice sistemático de Acuerdos de Actas capitulares de la ...ciudad de Cádiz, Padre de la Patria (1717-1807). Cádiz: Editorial Cerón, 1941. FALCÓN MÁRQUEZ, Teodoro. Torcuato Benjumeda y la arquitectura neoclásica en Cádiz. Cádiz: Diputación provincial, 1974.
} 
Ximénez entre 1777-79, que se conserva en el Museo Histórico Municipal. Para su realización se emplearon maderas nobles (caoba y ébano), márfil, hilo de seda y plumas. El tablero ocupa una superficie de 25 m.2. La maqueta es desmontable, como algunos de sus edificios singulares, a fin de poder apreciar detalles de su interior ${ }^{3}$. Rompe la escala uniforme de la edificación la mole de la catedral, de marfil, que refleja los proyectos barrocos de vicente Acero (1722) y de Torcuato Cayón, que se estaba ejecutando en ese momento. Esa escala de la catedral se reduciría en el cambio del siglo XVIII al XIX, rebajándose la altura de las torres y cúpulas, que se concluyeron bajo la estética neoclásica. Estas obras no se ultimaron en el edificio real hasta 1838, empleándose otros materiales menos nobles. Si en este período alcanzó Cádiz y su bahía su cénit, inmediatamente a partir de 1792 se inició un paulatino ocaso, a causa de los decretos de libertad del comercio, a la guerra con Inglaterra (batalla de Trafalgar, 1805); el sitio de Cádiz por los franceses (1808-12) y la emancipación de las colonias americanas. Todos estos hechos dilataron la conclusión de algunos edificios o no se ejecutaron diversos proyectos ${ }^{4}$.

Desde el punto de vista urbanístico Cádiz era una ciudad-puerto, que experimentó entonces un importante cambio de orientación. La ciudad deja de mirar hacia la bahía, con una Puerta del Mar, para construirse una nueva fachada hacia el istmo, Puerta de Tierra. Por otro lado, al hallarse en estado permanente de guerra, se convierte además en una ciudad-fortaleza, envolviéndose con un nuevo recinto amurallado, guarnecido de diversos baluartes y baterías. Complemento de esta fortificación tuvo que albergar a diversos batallones, lo que le indujo a convertirse asimismo en una ciudad-cuartel. Para ejecutar todos esos dispositivos, contó con la colaboración especial de ingenieros militares, quienes crearon un tipo de arquitectura más racional y menos ornamentada. Como en el resto de ciudades españolas su campo de acción fue diverso, ya que intervinieron en fortificaciones, defensas costeras, fábrica de tabacos, atarazanas, fundición de artillería, fábrica de salitre, pabellones militares, puertas de ciudades, aduanas, arquitectura religiosa, hospitales, casas de moneda, reales alcázares y faros, entre otras edificaciones. La labor que desempeñaron en esta ciudad a lo largo de este período podríamos denominarla de estética protoneoclásica. De

\footnotetext{
3 FALCÓN MÁRQUEZ, Teodoro. La Bahía de Cádiz en tiempos de Carlos III. Catálogo de la Exposición. Cádiz: Consejería de Obras Públicas y Transportes de la Junta de Andalucía y Ayuntamiento de Cádiz, 1988, pp. 40-42. Ibidem. El litoral andaluz en tiempos de Carlos III. Catálogo de la Exposición. Málaga: Consejería de Obras Públicas y Transportes de la Junta de Andalucía y Diputación de Málaga, 1988, pp. 24-26. MARTÍNEZ MONTIEL, Luis F.. La maqueta de Cádiz, algunos aspectos sobre la construcción y su autor. En Laboratorio de Arte 12. Sevilla, 1999, PP. 279-291. RUIZ NIETO-GUERRERO, María del Pilar y JIMÉNEZ MATA, Juan. Historia urbana de Cádiz. Cádiz, Colegio de Arquitectos, 2016, p. 193.

4 RAMOS SANTANA, Alberto. Cádiz en el siglo XIX. Editorial Silex, 1992.
} 
sus principales artífices destacaremos la labor desarrollada por José Barnola, Juan Martín Cermeño, Silvestre Abarca, Juan Caballero y Antonio Hurtado, entre otros ${ }^{5}$.

\section{EL PAPEL DE TORCUATO CAYÓN}

Torcuato Cayón de la Vega (1725-1783) fue un maestro de maestros. Es el arquitecto que marca la transición de la arquitectura barroca a la neoclásica en Cádiz y su zona de influencia. Nació en esta ciudad el 18 de noviembre de 1725. Fue discípulo de Vicente Acero y de su tío Gaspar Cayón. A su vez sería el maestro de su ahijado Torcuato Benjumeda y de Miguel de Olivares en la Escuela que estableció en su casa. En la arquitectura religiosa fue aparejador de la catedral nueva, a las órdenes de su tío Gaspar. En 1757 fue nombrado maestro mayor de este templo. En este apartado diremos que entre 1767-68 reconstruyó la torre de la iglesia de San Juan de Dios, anexa al Ayuntamiento; en 1770 proyectó la iglesia de San José de Puerto Real. Tres años después inició las obras de la iglesia de San Juan Bautista de Chiclana. En 1781 las de San José y San Pablo de Cádiz y, al siguiente la Santa Cueva, más la ampliación de la iglesia del Rosario. Como veremos, estos templos serían ultimados por Torcuato Benjumeda. Se conserva un retrato de Cayón en la cripta de la nueva catedral. Es de pintor anónimo y sin fecha. Se le representa vestido con casaca, sentado tras una mesa, sobre la que proyecta una planta. La pintura ha sido restaurada, habiéndose cambiado varias veces de sitio y de fecha. Pintada en el lienzo consta la siguiente inscripción: TORCUATO/CAYÓN DE LA/VEGA FUNDÓ/ESTA CAPILLA/AÑO DE 1787. Recordemos que falleció en 1783, que el cuadro estuvo en la desaparecida capilla de San Antonio de San Fernando, que se iniciaba cuando falleció, y que con posterioridad se depositó en la catedral de Cádiz. De este lienzo se hizo una litografía que figura en el Nomenclator de las calles de Cádiz, publicado en 1856 por Manuel de la Escalera (pseudónimo de Adolfo de Castro) ${ }^{6}$. Por la edad cronológica que representa, el retrato debió realizarse en 1757 (en la restauración se cambió el 5 por un 8), cuando fue nombrado maestro mayor de la catedral. Entonces tenía 32 años, era rubio, con una melena que cubre sus orejas. Lo de "fundó esta capilla" puede interpretarse que el cuadro estuvo en la Capilla del Sagrario de la catedral vieja, que había reformado en 1751.

5 CALDERÓN QUIJANO, Juan Antonio. et al. Cartografía military marítima de Cádiz(1513-1878). Sevilla: Universidad, 1978. FALCÓN MÁRQUEZ, Teodoro. La arquitectura en Andalucía al final del Barroco. Entre la tradición y la modernidad. En Actas del Congreso Internacional Andalucía Barroca. Junta de Andalucía, 2007, vol.I, pp. 49-66. CRUZ FREIRE, Pedro. Silvestre Abarca, un ingeniero militar al servicio de la monarquía hispana. Sevilla, Athenaica, 2018. RUIZ NIETO y JIMÉNEZ MATA. op. cit., PP. 143-149, 199-201, 278.

6 SOLÍS LLORENTE, Carlos. El retrato de Torcuato Cayón. En Anales de la Real Academia de Bellas Artes de Cádiz, nº 9. Cádiz, 1991, pp. 149-155. 


\section{Imagen 1}

\section{Antiguo Hospicio de Cádiz. Torcuato Cayón, 1763}

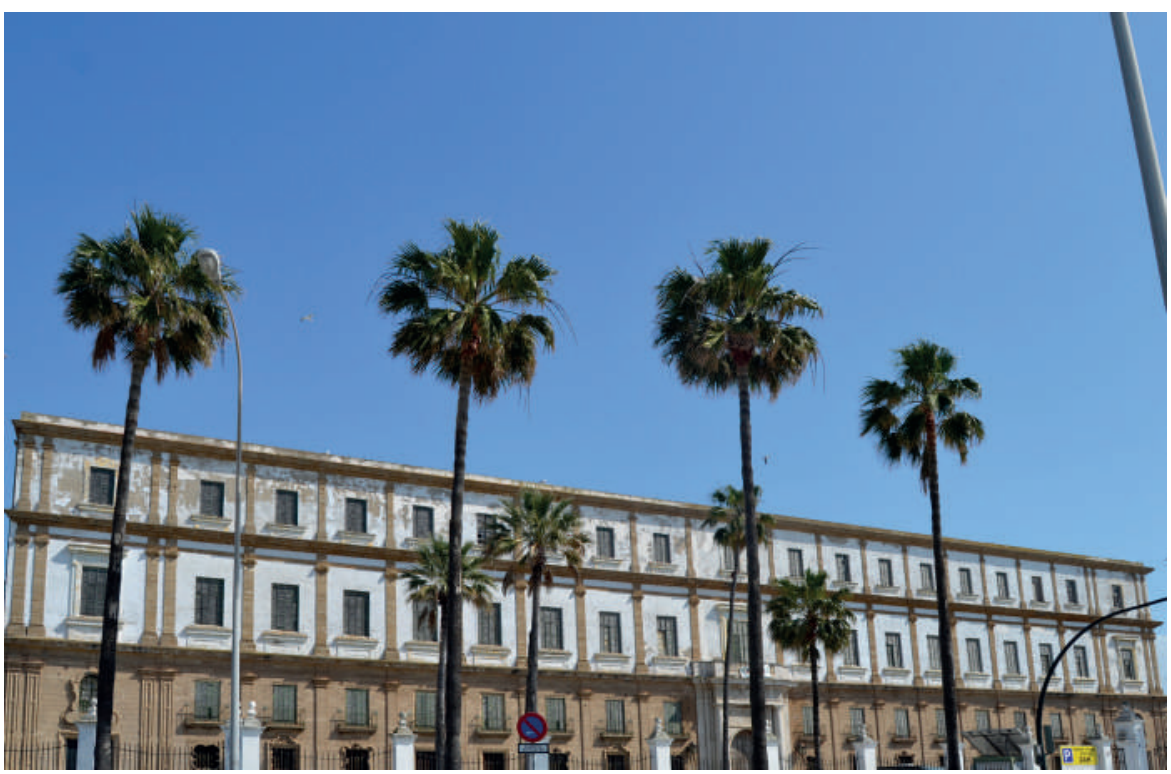

Autor: Juan Antonio Carpio Galnares

Respecto a la arquitectura civil reconstruyó Puerta de Tierra en 1756. Obtuvo en 1763 el título de Académico de Mérito de San Fernando de Madrid. En ese año acabó el Hospicio de Cádiz; en 1767 fue nombrado arquitecto mayor del Ayuntamiento de Cádiz y en 1778 proyectó e inició el Ayuntamiento de San Fernando. De su obra destacaremos el antiguo Hospicio de la Caridad, ubicado frente a la Caleta y al castillo de Santa Catalina. El hospicio está poco documentado; sabemos que data de 1763 (Imagen 1). Se trata de un edificio exento, de gran volumetría, de planta rectangular, que mide $85 \mathrm{~m}$. de frente, 68 de fondo y 22 de alto. Es de tres plantas, con fachada decorada con pilastras con superposición de órdenes. Tiene portada de mármol blanco, enmarcada por columnas dórico-toscanas. Al exterior la única nota barroquizante son las ventanas del cuerpo bajo, con baquetones mixtilíneos, que se relacionan con las de la catedral, de donde era maestro mayor. A eje con la puerta principal hay un esquema compositivo que recuerda el de El Escorial, con un patio y al fondo la iglesia, de la que solo se construyó la fachada. Es de estilo neoclásico, muestra un orden gigante de pilastras jónicas, en cuyos intercolumnios hay balcones con alternancia de frontones triangulares y semicirculares rebajados. En el cuerpo bajo hay un triple arco que accede al nártex. El conjunto se remata en un frontón triangular. El edificio experimentó una remodelación en la década de 1860 y, con posterioridad, en 1960 para albergar la institución “Ro- 
dríguez Valcarcel". En una de sus alas surgió el Colegio Universitario, origen de las Facultades de Ciencias y de Filosofía y Letras. En la actualidad se proyecta adecuarlo íntegramente a centro universitario ${ }^{7}$. Volviendo a la biografía del arquitecto, diremos que su hija Micaela Cayón Santaman se casó con el famoso arquitecto neoclásico Ventura Rodríguez. Torcuato falleció en la Isla de León (San Fernando) el 11 de enero de 1783. Al año siguiente, en 28 de septiembre de 1784, se hizo el reparto de bienes entre su familia ante el escribano Francisco de Huertas. En el Inventario, además de sus bienes, figura en el no 84: “Cuatro diseños del Hospicio de Cádiz, con cristal y marco dorado, evaluado en 240 reales de vellón". De los libros que tenía en su biblioteca citaremos: "Un libro de marquetilla de Vitrubio". Marco Vitruvio Marrón (s. I a. J.C.) es autor De architectura (conocido como Los Diez Libro de Arquitectura, del que se han hecho gran número de ediciones desde el siglo XVI, siendo la primera española en 1582); "El libro de Arquitectura de Alberti" (De re aedificatoria, de León Battista Alberti, h. 1450. Edición castellana de 1582 y 1593); "Un libro en italiano titulado Iconología de Ripa" (Iconología o vero imagini universali, de Cesare Ripa. Roma, 1593 (1 a edición); “la Geometría de Euclides" (Elementos); “el Tratado de Arquitectura de Palladio" (I quattro libri dell'Archittetura, de Andrea Palladio, Venecia 1570; edición española en 1625); “Un cuaderno no 8 de Vignola” (Jácomo Barozzi da Vignola, 1507-1573, fue el autor del Tratado de los Cinco Órdenes de la Arquitectura, publicado en 1562, con edición española de Patricio Caxés en 1593); “Un libro de marca mayor de Fontana, titulado Templum Vaticanum"(Templum Vaticanum et ipsius origo Rome, de Carlo Fontana, puede ser la edición de Giovanni Francesco Buagni, Roma 1694); la Fortificación de Guarino" (que debe ser Disegni d'Architettura civile et ecclesiastica, de Guarino Guarini, ediciones de 1686 o 1737); “Un libro con la obra del Padre Pozo” (Perspectiva pictorum et architectorum...1683-1686, del Padre Andrea Pozzo). Asimismo destacaremos: “Un libro que contiene la descripción del Escorial". Debe tratarse del Sumario y breve declaración de los diseños y estampas de la fábrica de San Lorenzo de El Escorial, realizado con proyectos de Juan de Herrera, grabados por Pedro Perret, publicado en Madrid en 1589, por la viuda de Alonso Gómez. También se cita “Unos libros de la obra del Padre Tosca”. Se trata de Tomás Vicente Tosca y Mascó (1651-1723), autor de un Compendio Mathemático (1707-1715, en 9 tomos, del que destacamos el V: Arquitectura civil, Montea y Cantería, Arquitectura militar, Pirotécnia o Artillería ${ }^{8}$.

7 RUIZ NIETO Y JIMÉNEZ MATA. op.cit. pP. 290-291.

8 FALCÓN MÁRQUEZ, T. Torcuato Benjumeda...op.cit. pp. 46-48. ANTÓN SOLÉ, P. El arquitecto gaditano Torcuato Cayón en el II Centenario de su muerte. En Anales de la Real Academia de Bellas Artes de Cádiz. Cádiz, 1983, vol. I. JIMÉNEZ MATA, Juan y MALO DE MOLINA, Julio. Guía de Arquitectura de Cádiz. Cádiz: Colegio Oficial de Arquitectos, 1995, Pp. 147148. MARTÍNEZ MONTIEL, Luis F. El testamento de Torcuato Cayón. En San Fernando, ciudad de las luces. Arquitectura $\gamma$ urbanismo (1766-1868). Publicaciones del Sur, Pp.298-303. MUÑOZ REY, Yolanda. El testamento de Torcuato Cayón. En ArtyHum $n^{\circ}$ 40, pp. 123-139. 


\section{PROTAGONISTAS DEL NEOCLASICISMO EN CÁDIZ}

El Neoclasicismo fue un arte oficial y elitista, propiciado por una burguesía erudita. Uno de los puntos de partida se halla en la creación en 1752 de la Academia de San Fernando de Madrid, inspirada en modelos franceses. Su eco se hizo más palpable en Cádiz a partir de los reinados de Carlos III y Carlos IV, hasta Fernando VII. El detonante fue la Real Orden de 25 de noviembre de 1777, por la que se establece la obligatoriedad de que todos los proyectos de obras, incluidos los retablos, tenían que ser aprobados por esa academia. Esta institución asimismo supervisaba los exámenes de los arquitectos y maestros de obras de las ciudades y cabildos. Sin embargo, el control no fue asumido plenamente hasta la constitución de la Junta de la Comisión de Arquitectura en 1786. La renovación de la arquitectura con el nuevo lenguaje clásico vino, de una parte, a través de los modelos que difundían algunos arquitectos que trabajaban en Madrid, empleando los nuevos preceptos estéticos dimanados de la Academia de San Fernando. Entre ellos hay que destacar el papel que desempeñó Ventura Rodríguez, seguido por una serie de arquitectos pensionados en Roma, así como por Juan de Villanueva y Silvestre Pérez. En Andalucía el triunfo del neoclasicismo fue escaso y puntual, representando el papel de abanderados algunos académicos provinciales, ingenieros militares, miembros de las Reales Sociedades Económicas de Amigos del País, determinados ayuntamientos, así como políticos, munícipes y pensadores ilustrados. En Cádiz la Escuela de Bellas Artes tuvo su antecedente en una particular de Dibujo, creada en 1777 por el Gremio de Plateros. En 1785, con el patrocinio del conde de O'Reilly, se refundió con otra de Dibujo y Aritmética. En 1789 obtuvo el rango oficial por mediación del gobernador Fondesviela, con el título de las Tres Nobles Artes. Sin embargo hasta 1836 a la Escuela no se le concedió la categoría de Academia, gracias a las gestiones del conde de Maule y de Tomás de Sisto, secretario de la Escuela.?

Entre las personalidades que contribuyeron a difundir el neoclasicismo en Cádiz y su entorno, destacaremos a José Sáenz de Santa María, II marqués de Valde-Íñigo (1738-1804). Sacerdote, heredero de una importante herencia familiar, y gran coleccionista, fue el promotor de la construcción de la Santa Cueva. Se trata de un solar en el que al parecer hubo una cueva donde se le había dado culto a la diosa Astarté. A sus expensas mandó construir dos tem-

9 ANTÓN SOLÉ, P. El Cádiz del conde de O'Reilly. En Cádiz en la Carrera de Indias. Boletín del Aula Militar de Cultura. Cádiz, 1967. GASCÓN HEREDIA, María Teresa. Estudio histórico de la Escuela de Nobles Artes de Cádiz (1789-1842). Cádiz, Academia de Bellas Artes, 1989. 
plos superpuestos. El inferior dedicado a la Pasión y Muerte de Cristo, y la capilla superior a la Eucaristía. Es de planta elíptica y su espacio se conviertió en uno de los prototipos de la arquitectura neoclásica en la ciudad. En ella se conserva un retrato del benefactor, realizado en 1796 por Franz Xaviert Riedmayer, además de tres lienzos de Goya. El marqués se halla enterrado en este templo ${ }^{10}$. También hay que destacar a Gaspar de Molina y Zaldivar (1741-1806), más conocido como marqués de Ureña. Fue un hombre ilustrado: arquitecto, ingeniero, físico, militar, músico, pintor y viajero, autor de Reflexiones sobre la arquitectura y ornato del templo (Madrid, 1785). Fue académico de las Reales de la Historia, de la Lengua y de Bellas Artes de San Fernando, así como consiliario de la de Cádiz ${ }^{11}$. Se le encargó la comandancia y dirección de la población de San Carlos. En 1791 firmó los primeros planos del Observatorio de San Fernando, proyectando otros Vicente Tofiño. Ureña le encargó al arquitecto José Prat la dirección de las obras en 1793. El Observatorio se trasladó a este espléndido edificio neoclásico en $1798 .^{12}$

Otro personaje insigne fue Tomás de Sisto y Váccaro (1778-1826). Hombre polifacético: militar, ingeniero, pintor y dibujante. Llegó a ser consiliario de la Escuela de Nobles Artes de Cádiz y autor de Principios de Arquitectura editados según el sistema de Vignola para uso de los alumnos de la Academia de las Tres Nobles Artes (Cádiz, Imprenta del Estado Mayor General, 1813). Otra obra impresa muy importante fue la Colección de Vistas iluminadas de los principales edificios de Cádiz, con una breve noticia de su fundación, destino y mérito artístico de sus fábricas (Cádiz, 1815). La publicación está ricamente ilustrada. Asimismo fue Secretario de la Sociedad Económica de Amigos del País ${ }^{13}$. También hay que destacar a Nicolás de la Cruz Bahamonde (1757-1828), más conocido por conde de Maule. Fue un español nacido en Chile quien llegó a ser militar, alcalde constitucional de Cádiz en 1812, diputado en Cortes por Chile en 1821, distinguido como Caballero de la Orden de Carlos III. Afincado en Cádiz desde 1784 hasta su muerte, se dedicó al comercio, junto a su hermano. Quedó vinculado a la historia de esta ciudad y su bahía como benefactor, así como historiador y viajero. Es autor de Viage por España,

10 LEÓN ALONSO, Aurora, CRUZ VALDOVINO, José María. La Santa Cueva de Cádiz. Madrid: Fundación Caja Madrid, 2001.

11 VIRGINIA SANZ, María Mercedes. El marqués de Ureña y el neoclasicismo gaditano. En Goya, nº 151. Madrid, 1979, Pp. 209-220.

12 FALCÓN. La Bahía de Cádiz... op. cit. no 35. MILlÁN CHIVITE, José Luis. La población de San Carlos. En Enciclopedia Gráfica gaditana. Cádiz, Caja de Ahorros, 1984, PP. 33-48. LAFUENTE, Antonio, SELLÉS, Manuel. El Observatorio de Cádiz (1753-1831). Madrid, Ministerio de Defensa, 1988. MARTíNEZ MONTIEL. Luis F. El Observatorio Astronómico de San Fernando (1789-1869). Sevilla, La Voz, 1989.

13 OSSORIO Y BERNARD, Manuel. Galería biográfica de artistas españoles del siglo XIX. Madrid, 1975. GASCÓN HEREDIA, María Teresa. Estudio histórico de la Escuela de Nobles Artes de Cádiz...op.cit. DE LA BANDA Y VARGAS, Antonio. El neoclasicismo en la provincia de Cádiz En Provincia de Cádiz. Sevilla: Ediciones Gever, 1985, vol. III, pp. $207-216$. 
Francia e Italia, que realizó entre 1797-99, publicado en 1813 en 14 tomos (en la Imprenta de Manuel Bosh). Uno de ellos está dedicado a la historia de Cádiz (tomo XIII). En él alude al comercio en esta ciudad y a la vivienda que tenía en la plaza de la Candelaria ("Casa Ovidio"), en la que poseía una importante biblioteca y amplísima pinacoteca de 300 cuadros. Como destacado mecenas contribuyó económicamente a la construcción de las iglesias de San José y del Rosario, en Cádiz, y a la de San Juan Bautista, de Chiclana. Fue Correspondiente de la Academia de la Historia, Honorario de la de San Fernando de Madrid y Consiliario de la de Bellas Artes de Cádiz. Se conserva un retrato suyo, con una vista de Chiclana, realizado por Franz Xavier Riedmayer, en 1806. ${ }^{14}$ La evolución de la arquitectura neoclásica en Cádiz y su provincia se vio fortalecida al establecerse en esta ciudad una serie de arquitectos venidos de fuera, tales como el vasco Pedro Ángel Albisu, el madrileño Manuel Machuca y el catalán Juan Daura.

Pedro Ángel Albisu Lizarralde (1752-1817) era natural de la villa de Zumárraga (Guipuzcoa), en donde fue bautizado en la iglesia parroquial de la Asunción el 6 de septiembre de $1752^{15}$. Formado en la Academia de San Fernando de Madrid, esta institución le concedió el título de Académico Supernumerario en 1780. Afincado en la Isla de León, trabajó en el Arsenal de La Carraca. En 1783 al fallecer Torcuato Cayón, solicitó la vacante de arquitecto mayor de Cádiz, acompañando una relación de méritos y una certificación de Antonio Ponz, secretario de la Academia de Madrid. Desempeñó este oficio en Cádiz hasta diciembre de 1807, cuando fue jubilado por "sus muchos achaques". Fue Director de Arquitectura de la Academia gaditana hasta 1816. En esta capital destacaremos el proyecto del Matadero Municipal, fechado en 15 de junio de 1803, cuya obra se concluyó dos años después ${ }^{16}$. También realizó el proyecto del retablo mayor de la iglesia del convento de San Agustín (1783) y edificó la sacristía de la Colegiata de Jerez en $1817^{17}$.

\footnotetext{
14 FALCÓN MÁRQUEZ, Teodoro. Arquitectura neoclásica en Cádiz. En Diccionario Enciclopédico Ilustrado de la provincia de Cádiz. Jerez: Caja de Ahorros, 1985, vol. IV, p. 57. Ibidem. La iglesia de San Juan Bautista de Chiclana. II Centenario (1814-2014). En Trocadero 26, pp. 197-219. RAVINA MARTÍN, Manuel. Conde de Maule. De Cádiz y su comercio. En la edición y estudio preliminar del Viage de España...vol. XIII. Cádiz: Universidad, 2016. RUIZ NIETO y JIMÉNEZ MATA. op.cit. pp. 162-165.

15 Archivo parroquial de la iglesia de la Asunción, Zumárraga. Libro $5^{\circ}$ de Bautismos, f. 110 v. (al margen: Pedro Ángel Albisu): "En seis de Septiembre de mil settecientos cinquenta y dos bapticé a Pedro Ángel, hijo legítimo de Francisco de Albisu y Agustina de Lizarralde; Abuelos paternos: Francisco de Albisu, mayor en días, y María Asencia de Balenciaga; Maternos: Gabriel de Lizarralde y Josepha de Aryazaga; Padrinos: Pedro de Mendizabal, y Josepha de Goenaga, y fueron havisados de lo que dispone el Manual Romano, y firmé. Don Juan de Echebarría".

16 Archivo Municipal de Cádiz (AMC). Planta y dos fachadas de la Casa del Matadero. Planos de alzados de casas desde 1801 a 1805 . Cajón $2^{\circ}, n^{\circ}$ 9. Libro 7, VI.

17 FALCÓN MÁRQUEZ, Teodoro. Biografía de Pedro Ángel Albisu, arquitecto mayor de Cádiz. En Homenaje al profesor Carriazo. Sevilla, Universidad, 1972, tomo II. Ibidem. Torcuato Benjumeda...op.cit., Pp. 48-50. Ibidem. Arquitectura neoclásica en Andalucía. En Gran Enciclopedia de Andalucía, nº 102. Sevilla, 1979, pp. 2534-2537. CIRICI NARVÁEZ, Juan Ramón. Juan de la Vega. Arquitectura gaditana del siglo XIX. Cádiz: Colegio de Arquitectos, 1992, pp. 39-40.
} 
Otro arquitecto foráneo notable fue Manuel Machuca y Vargas (1750-1799). Este madrileño se formó también en la Academia de San Fernando y en el estudio de Ventura Rodríguez. Fue arquitecto del Real Sitio del Buen Retiro. Tras diversos trabajos en la provincia de Madrid, en 1787 fue nombrado teniente director de Arquitectura de la citada Academia. En ese año el conde de Floridablanca lo envió a Cádiz para inspeccionar las obras de la nueva catedral, siendo tres años después nombrado "arquitecto principal por S.M.". Al mismo tiempo se nombró como arquitecto adjunto a Miguel de Olivares. Poco pudieron avanzar ambos, más allá de levantar planos y resolver problemas de cómo terminar la fachada principal, los cuerpos superiores de las torres, la bóveda del trascoro y la cúpula del cimbórrio, ya que las obras estuvieron interrumpidas entre 1796 y 1832 por la guerra con Inglaterra ${ }^{18}$. Su proyecto de conclusión de este templo (1789), ofrecía un acusado acento romano y renacentista, especialmente en el modelo de la cúpula, con ecos de la basílica de San Pedro del Vaticano y de El Escorial. En 1795 recibió el encargo por la Academia de San Fernando, de traducir el Tratado de Palladio, cuya obra quedó sin terminar ${ }^{19}$.

Juan Daura Jover (1791-1844) fue un catalán, nacido en Plá de Cabra (Tarragona), quien llegó a ser arquitecto, militar e ingeniero. En 1831 obtuvo el título de arquitecto por la Academia de San Fernando. Al año siguiente se estableció en Cádiz, donde solicitó la plaza de segundo arquitecto mayor de la ciudad, cargo inexistente, que fue aceptado de forma provisional a causa de la avanzada edad de Torcuato Benjumeda. Tras el fallecimiento de éste en 1836 le sucedió en el cargo. Desde entonces su cometido fue proseguir o finalizar las obras inacabadas por su predecesor en el Ayuntamiento, y de Olivares en la catedral. En 1832 se puso al frente de este templo, construyendo la gran cúpula semiesférica de ladrillo, revestida de azulejos dorados, sin linterna. En 1836 concluyó la Cárcel Real, proyectada y en gran parte construida por Benjumeda. Al año siguiente inició la construcción del Mercado de Abastos, según proyecto de Benjumeda en la Plaza de la Libertad, y construyó el edificio que alberga la Academia y el Museo de Bellas Artes en la Plaza de Mina, concluido en 1852 y rehabilitado en 1984. Por su cronología la obra de Daura evolucionó desde el neoclasicismo hasta el estilo isabelino 20 .

18 ANTÓN SOLÉ, Pablo. Catálogo de Planos, Mapas y Dibujos del Archivo Catedralicio de Cádiz. Cádiz, Ayuntamiento, 1976. Ibidem. La catedral nueva de Cádiz. Estudio histórico y artístico. Cádiz, Ayuntamiento, 1976.

19 NAVASCUÉS PALACIO, Pedro. La formación de la arquitectura neoclásica en la época de la Ilustración. En Historia de España de Menéndez Pidal. Madrid, Espasa-Calpe, 1987, vol. VI, pp. 655-717. CIRICI .Juan de la Vega...op.cit, pp.176-181. JIMÉNEZ MATA, Juan. Vicente Acero $\gamma$ la catedral nueva de Cádiz. Cádiz, Quorum Editores, 2012.

20 FALCÓN. Torcuato Benjumeda...op.cit., PP. 51-53. CIRICI. La arquitectura gaditana...op.cit., pp. 42-50. JIMÉNEZ MATA. Vicente Acero...op.cit. 
De los arquitectos neoclásicos naturales de la provincia de Cádiz, destacaremos a Torcuato Benjumeda y Miguel de Olivares. Miguel de Olivares Guerrero (1748-1819) era natural de Ubrique. Su formación se inició bajo la tutela de Torcuato Cayón, en la Escuela que tenía en su casa, siendo condiscípulo de Benjumeda. Cayón le nombró aparejador de la Colegiata de Jerez en 1772, interviniendo en la construcción de la cúpula. Dirigió las obras de este templo entre 1778 a 1780. En ese período se consagró la iglesia el 16 de diciembre de 1778, aunque después prosiguieron. Entre sus proyectos destaca la portada de la sacristía, realizada en 1798. A la muerte de su maestro fue nombrado maestro mayor de la catedral de Cádiz, cuando todavía estaba pendiente la conclusión de la fachada principal y las torres. Fue nombrado miembro de la Academia de San Fernando en 1787. El edificio civil más importante que proyectó fue la casa de Fernando Antonio Pazos de Miranda, en la plaza de San Juan de Dios $n^{0} 11$, fechado en enero de 1795.Se trata de un espléndido edificio exento, de cinco plantas, con decoración neoclásica, a base de paramentos almohadillados, altas pilastras jónicas, frontones que alternan los triangulares con los semicirculares rebajados y remates de jarrones de piedra. En la actualidad está destinado a oficinas municipales. Este arquitecto fue nombrado miembro de la Academia de San Lucas de Roma en $1799^{21}$.

\section{LA FIGURA ESTELAR: TORCUATO BENJUMEDA}

Torcuato José Benjumeda y Laguada (1757-1836) es la figura estelar de la arquitectura neoclásica en Cádiz y su zona de influencia. A él le dedicamos hace años una monografía ${ }^{22}$. Nacido en El Puerto de Santa María, se formó junto a su padrino Torcuato Cayón, de quien recibió el nombre, siendo condiscípulo de Miguel de Olivares. A partir de 1781, cuando tenía 24 años, sustituyó a Cayón en las tareas de maestro mayor de la ciudad, a causa de estar enfermo. El maestro falleció dos años después, por lo que prosiguió y ultimó algunos de los edificios religiosos que Cayón había proyectado ${ }^{23}$. En 1789 fue nombrado Teniente de Arquitectura de la Academia de Nobles Artes de Cádiz y tres años después supliólas ausencias

\footnotetext{
21 AMC. Planos. Cajón $2^{\circ}$. Libro 11. Con escala gráfica de 10 varas. Rubrican el proyecto: el arquitecto, el propietario y el regidor Huarte. FALCÓN. Torcuato Benjumeda...op.cit., lam. 10, pp. 50-51. CIRICI. Juan de la Vega...op.cit. pp.40-41.

22 FALCÓN. Torcuato Benjumeda...op.cit.; Ibidem. El examen de alarife de Torcuato Benjumeda. En Boletín del Museo de Bellas Artes de Cádiz. Cádiz, 1978, vol. 1. Idem. Arquitectura barroca y neoclásica (siglos XVII-XIX). En Diccionario Enciclopédico Ilustrado de la provincia de Cádiz. Jerez, Caja de Ahorros, 1987. Tomo I, Pp. 71-77. Ibidem. La iglesia de San Juan Bautista... op.cit, pp. 197-219. VILLANUEVA, Luis. Don Torcuato José de Benjumeda. En Revista Nacional de Arquitectura. Madrid, 1949, vol. VIII, pp. 48-50.; ANTÓN SOLÉ, Pablo. La etapa juvenil del arquitecto Torcuato Benjumeda y su tiempo. En Anales de la Real Academia de Bellas Artes de Cádiz. Cádiz, 1987, vol. V. RUIZ NIETO y JIMÉNEZ MATA. op. cit. 330 .

23 Según consta en el testamento de Cayón se le pagaron a Benjumeda 1.025 rs. de vn. por la asistencia y gestiones antes y después del fallecimiento de su maestro. Asimismo, percibió su ahijado "un reloj de plata con su cadena de lo mismo, valorada en 570 rs. de vn. y un espadín".
} 
del maestro mayor de la ciudad, Albisu. En 1793 fue nombrado académico de mérito de la Real de San Fernando de Madrid. Para la prueba de acceso envió unas trazas de un Consulado para una ciudad con puerto de $\operatorname{mar}^{24}$. Años después sería nombrado maestro mayor del Ayuntamiento de Cádiz en 1809 y, en 1816 presidente de la Academia de esta ciudad. Haciendo un breve resumen de su obra en la arquitectura civil, destacaremos los proyectos que hizo para la Cárcel Real de Cádiz (1794). (Imagen 2). Se trata no solo del edificio neoclásico más importante de esta provincia, sino de Andalucía. Su fachada se organiza con un cuerpo central avanzado con cuatro columnas dórico-toscanas, más dos alas laterales. El friso es dórico, con triglifos. Entre los esquemas compositivos figuran semicírculos con óculos en el centro. Su planta es un rectángulo que mide 66,87x 33,45 m.; se organiza en torno a un patio central y dos laterales.

\section{Imagen 2}

Antigua Cárcel Real. Torcuato Benjumeda, 1794

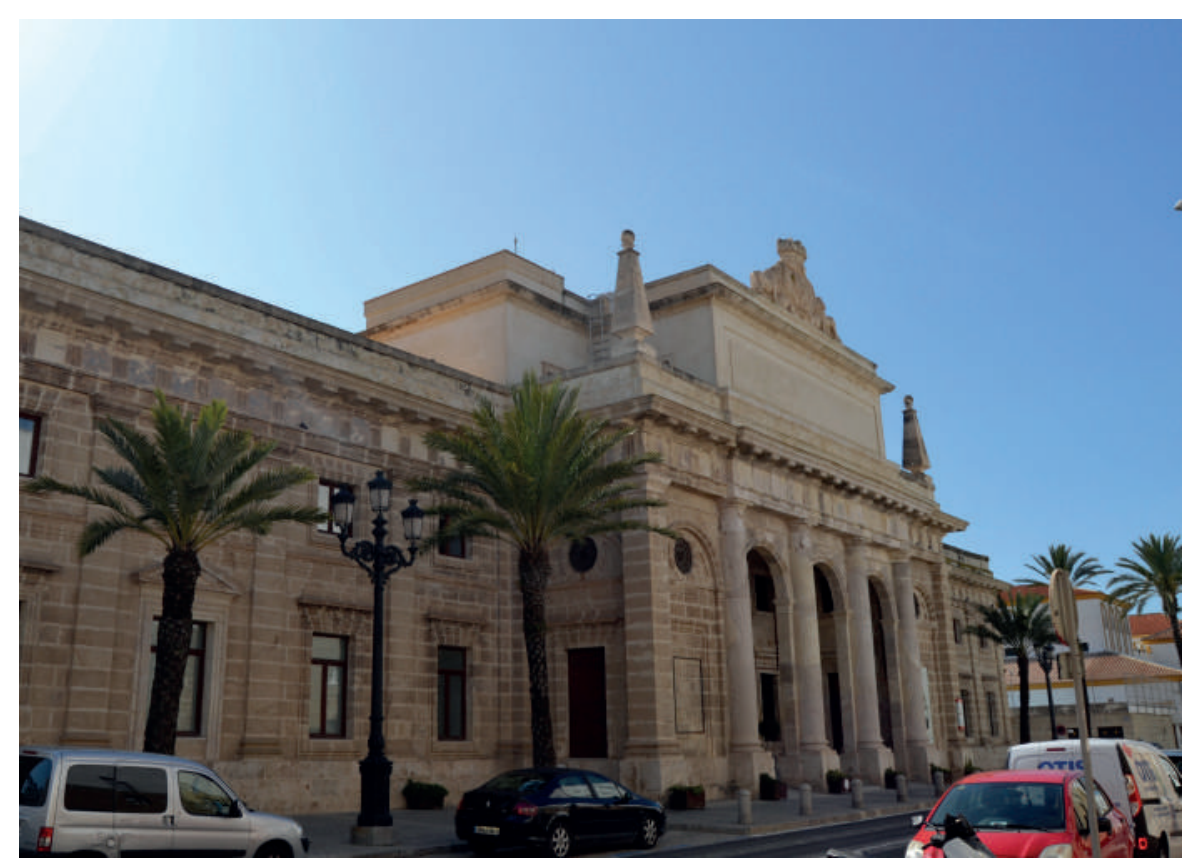

Autor: Juan Antonio Carpio Galnares

24 Archivo General de la Real Academia de Bellas Artes de San Fernando de Madrid (5-186-17): “Pruebas de acceso al título de académico de mérito. Torcuato José de Benjumeda, 1793. Informe facultativo sobre planos, vista del frente y perfiles de una casa de consulado magnífica en puerto de mar". Este nombramiento consta en el Archivo de la Academia de Bellas Artes de Cádiz. Libro I. Junta de 22 de noviembre de 1793. 
Benjumeda renovó el Ayuntamiento de esa ciudad, dotándole de la monumental fachada que hoy tiene a la Plaza de San Juan de Dios, ejecutada entre 1815-16 (Imagen 3). Entre su ornamentación figuran en relieve el reverso de monedas fenicias de Gadir, en las que se hallan uno o dos atunes, más leyendas en alfabeto fenicio. Según consta en un dibujo conservado en el Archivo Municipal, sirvieron de referencia monedas pertenecientes al conde de Río-Molino y otras familias gaditanas ${ }^{25}$. Asimismo, proyectó los alzados del patio. Muy interesantes son los proyectos que hizo para Panadería y Juzgado (1800), de un Molino de Pan (1807), el Cuartel de San Fernando (1807), el Mercado Municipal de la Plaza Nueva (Libertad, 1830) y el Cementerio municipal, en las dos primeras décadas del siglo XIX. El Cuartel de San Fernando lo proyectó Benjumeda en julio de 1807. Se encontraba en el barrio del Balón, sector que había sido urbanizado por este arquitecto. Se edificó por cuenta de la Casa de la Misericordia, en un terreno cedido por el conde de O'Reilly. Aunque previsto inicialmente como hospital de enfermedades venéreas, se habilitó para albergar tropas tras el bombardeo de la escuadra inglesa. Durante la Guerra de Independencia sirvió de alojamiento de los Voluntarios Distinguidos de Cádiz, recibiendo entonces el nombre de Cuartel de San Fernando. También fue cuartel de las milicias nacionales. El edificio fue derribado en 1900 , construyéndosoe en su lugar el Hospital civil, a expensas de don José Moreno de Mora (Hospital Mora), por Lucien Vicent en $1903^{26}$. Constaba de tres plantas, con monumental portada avanzada, con un primer cuerpo almohadillado con triple arco de acceso, más cuatro gigantestas columnas dórico-toscanas que enmarcaban los cuerpos superiores. Se remataba en un amplio fróntón triangular, con óculo central. El Mercado Público de la Plaza Nueva (hoy Mercado Central de Abastos en la plaza de la Libertad), tiene su origen en los proyectos realizados por Benjumeda en 1830, con destino al solar que ocupaba la huerta del convento de los Descalzos, recién desamortizado ${ }^{27}$. El proyecto neoclásico consistía en un edificio exento, de planta rectangular, con puertas en el centro de cada lado. Se trata de una construcción adintelada con un peristilo de grandes columnas dórico-toscanas, de más de cuatro metros de alto. El rectángulo mide aproximadamente 100x $55 \mathrm{~m}$. No lo pudo ejecutar su autor al hallarse con achaques. Tras el fallecimiento de Benjumeda en 1836, acometió su construcción al año siguiente Juan Daura. Con posterioridad el edificio fue rehabilitado por Juan Talavera entre $1926-27^{28}$.

\footnotetext{
25 FALCÓN. Torcuato Benjumeda...op.cit., pp. 66-68, lam. XVIII.
}

26 MORENO CRIADO, Ramón. El Cuartel de San Fernando. En Rincones gaditanos. Hoja del Lunes. Cádiz, 29 de septiembre de 1975.

27 AMC. Cajón $2^{\circ} \mathrm{n}^{\circ} 4$. Libro $3^{\circ}$, VII y Colección de don Carlos Solís.

28 FALCón. Torcuato Benjumeda... op.cit. lam. XX. CIRICI. Juan de la Vega...op.cit. pp. 49-50. 


\section{Fachada del Ayuntamiento de Cádiz. Benjumeda, 1816}

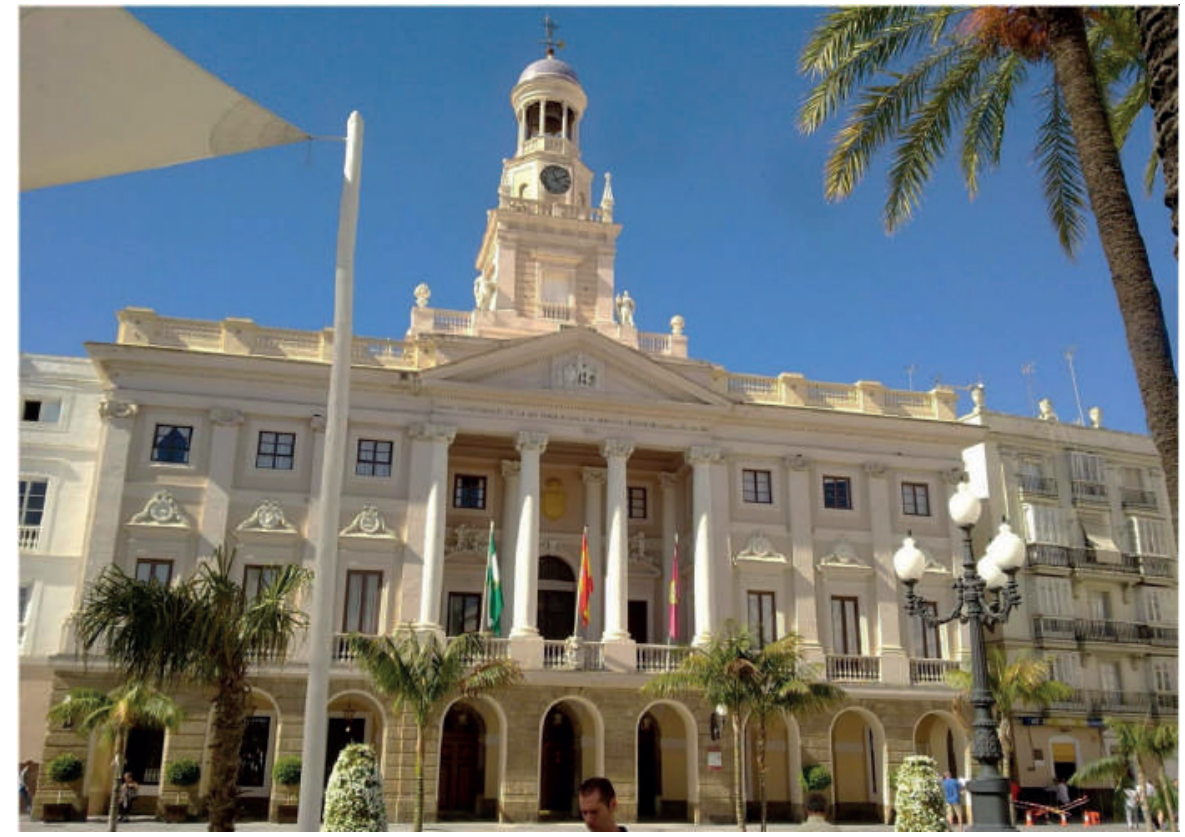

La iglesia de San José, las viviendas del barrio de este nombre y el Cementerio municipal, formaron parte de la política de expansión a extramuros, fuera de Puerta de Tierra, que se acometió desde el último tercio del siglo XVIII hasta las primeras décadas del XIX. La iglesia, proyectada por Torcuato Cayón, quedaría solo replanteada cuando falleció en 1783 (Imagen 4). Consta que al año siguiente estaba al frente de las obras Benjumeda, quien la dirigió hasta su conclusión en 1787. En su entorno surgió el barrio obrero a lo largo del siglo XIX. La construcción del cementerio respondía a la Real Cédula de 3 de abril de 1787, por la que se prohibía enterrar en los templos y se ordenaba la construcción de estos nuevos recintos en las afueras de la ciudad. En el caso de Cádiz, la necesidad imperiosa de su construcción se debió a los repetidos brotes de epidemia de peste en 1800, 1804 y 1813. Aunque su estreno provisional se hizo el 24 de agosto de 1800, tuvo que ampliarse paulatinamente según proyectos de Benjumeda fechados en 1802, 1803, 1815 y 1819. El conjunto se organizó en torno a varios patios. Por razones de espacio solo destacaremos aquí el proyecto no ejecutado, fechado en agosto de 1802, en el que figuraba una monumental capilla, de planta cuadrada, rematada en una cúpula semiesférica de ecos romanos y renacentistas, decorada interiormente con pilastras toscanas y frontones semicirculares con círculos inscritos. Según la escala gráfica iba a ser colosal, ya que mediría más de 30 m. de alto. Al exterior estaban 
previstas, a uno y otro lado, galerías porticadas sobre pilares. De estar previsto un monumental edificio neoclásico, el resultado final fue otro más modesto ${ }^{29}$.

\section{Imagen 4}

Iglesia de San José de Cádiz. Benjumeda, 1787

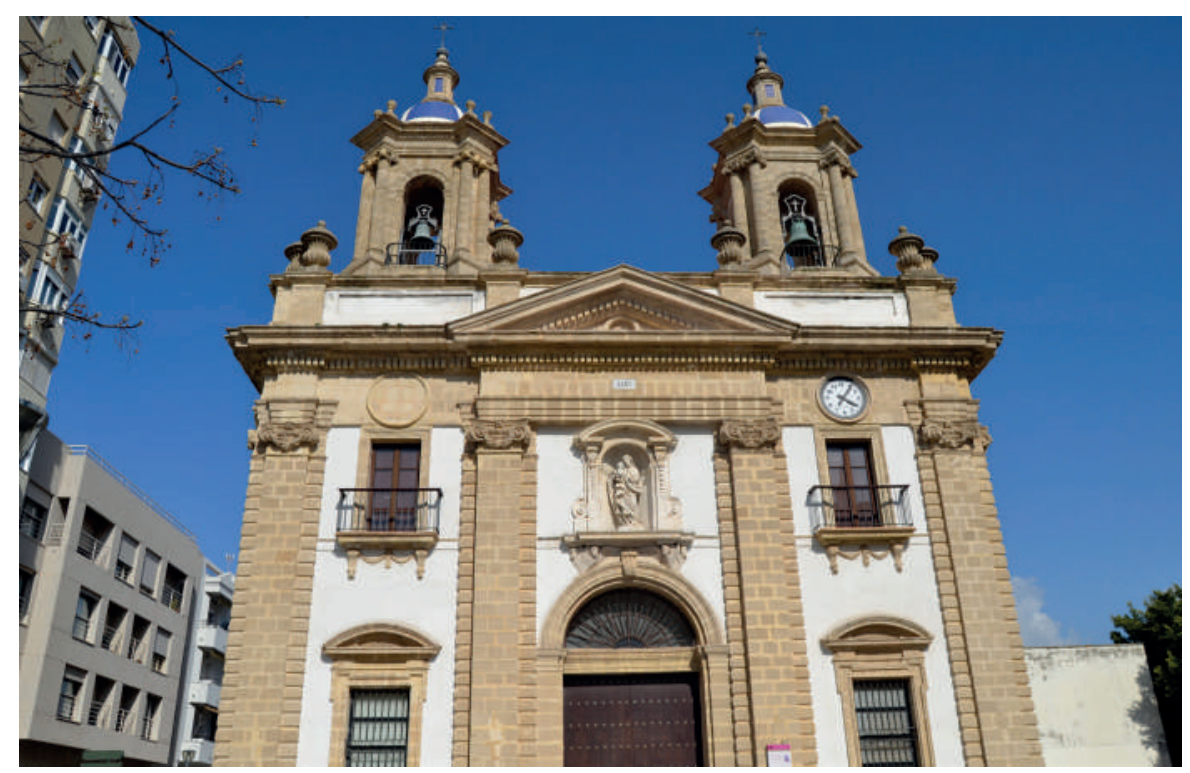

Autor: Juan Antonio Carpio Galnares

En la arquitectura religiosa destacaremos especialmente la monumental iglesia de San Juan Bautista de Chiclana, de la que ya publicamos los proyectos originales, fechados entre 1786 y $1806^{30}$ (Imagen 5) y la espectacular capilla sacramental de la iglesia de la Santa Cueva de Cádiz, de planta elíptica, construida en 1796, en donde se hallan tres pinturas de Goya $^{31}$. Benjumeda testó el 2 de abril de 1836 ante el escribano público José García de Meneses. Falleció el día 15 de ese mes y año, cuando tenía 79 años. Fue enterrado en la iglesia de San Lorenzo de Cádiz ${ }^{32}$. De este arquitecto se conserva un retrato realizado por Juan Rodrí-

29 FALCÓN. Ibidem.pp. 76-77, 88-89. RUIZ NIETO y JIMÉNEZ MATA. op. cit. pp. 330-335.

30 FALCÓN. Ibidem. Lams. XXXI a XXXIV. “La iglesia de San Juan Bautista...” op.cit., pp. 197-219.

31 LEÓN ALONSO, A.; CRUZ VALDOVINO, J.; ANTÓN SOLÉ, P. La Santa Cueva de Cádiz., op.cit.

32 Iglesia parroquial de San Lorenzo., Cádiz. Libro $8^{\circ}$ de Funerales. Da principio en 13 de marzo de 1830, f. 196. Cláusulas de testamentos de la parroquia de San Lorenzo, correspondientes al año 1836. Archivo episcopal de Cádiz. El testamento se conserva en el Archivo Histórico provincial de Cádiz. Aunque en él constan una serie de propiedades que poseía, sin embargo, no tenía liquidez, ya que era acreedor de numerosas sumas, debidas a no habérseles hecho efectivas la mayor parte de sus obras, ni en el cargo de arquitecto mayor de la ciudad, ni como presidente de la Academia. 
guez, El Panadero, fechado en 1813, cuando el arquitecto tenía 56 años. El lienzo $(1,24$ x 0,87) fue donado a la Academia gaditana por su hijo Francisco de Paula en 1861. En la actualidad está depositado en el Museo de Bellas Artes de esta ciudad. Viste con el uniforme de capitán de Voluntarios de Artillería, de la Compañía de Voluntarios Distinguidos, integrada por alumnos de la Escuela de Bellas Artes.

Imagen 5

Fachada de la iglesia de Chiclana. Benjumeda, 1786-1814

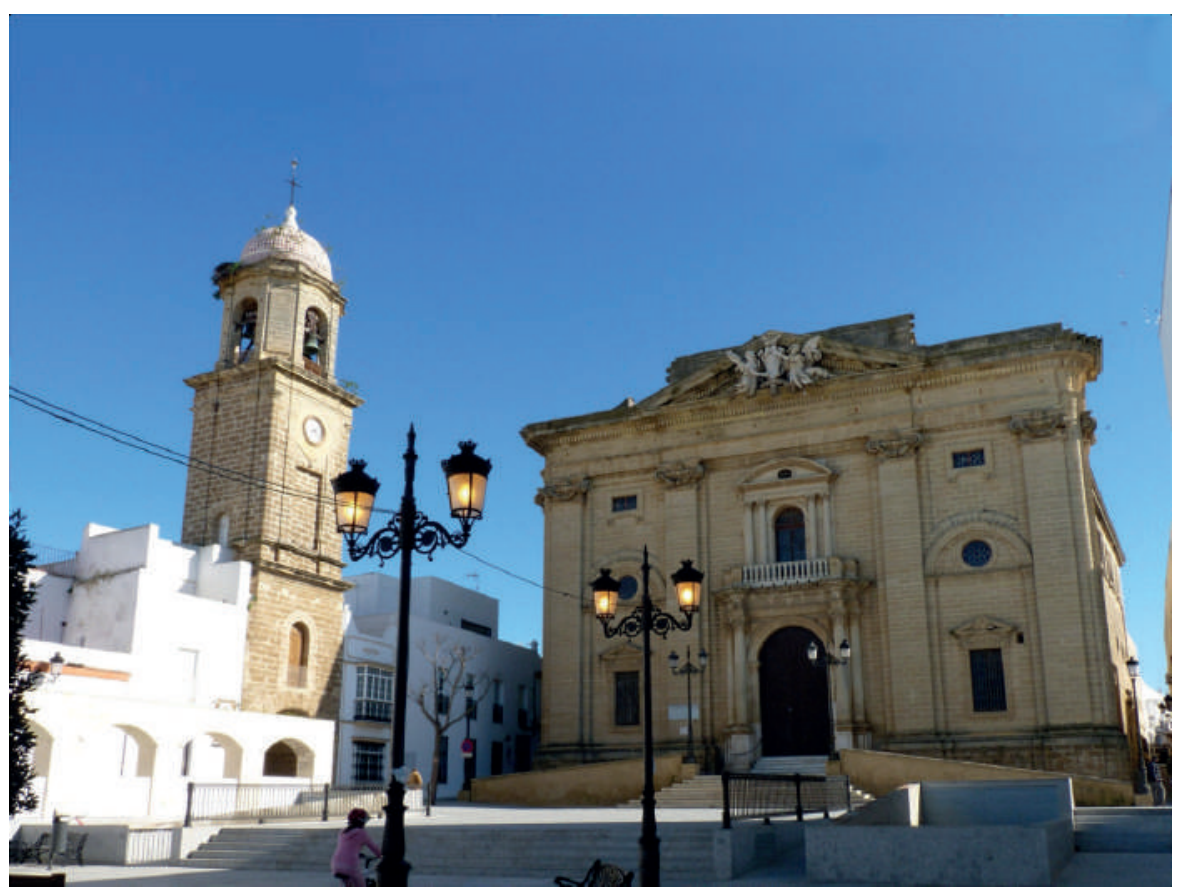

Los proyectos arquitectónicos de Benjumeda derivan en algunos casos de Torcuato Cayón, al tener que concluir edificios religiosos proyectados e iniciados por su maestro, pero decantando la ornamentación barroca y empleando motivos neoclásicos. Al formarse en la Escuela que tenía su padrino, obviamente consultó los libros de los tratadistas italianos que tenía en su biblioteca, tales como ediciones de Vitrubio, Alberti, Palladio, Viñola y el Templum Vaticanum, de Carlo Fontana. Del barroco italiano conoció sin duda la obra de Guarino Guarini, el tratado de perspectiva del P. Pozzo y la obra de Filipo Juvara. Del barroco español el tratado del P. Tomás Vicente Tosca y Mascó ${ }^{33}$ y publicaciones sobre la villa y corte de Madrid. Del neoclasicismo español se advierten ecos de la obra de Ventura Rodrí- 
guez, yerno del maestro, quien a su vez bebía en las fuentes de Juvara. Por otra parte tomó elementos decorativos de El Escorial y de la Lonja sevillana (Archivo de Indias), que a su vez Herrera había tomado de Sebastián Serlio ${ }^{34}$. El modelo de frontón triangular con un círculo en el centro, que figura rematando la fachada del monasterio de San Lorenzo, lo tomó Herrera de Serlio (lam. XXXV, LVIII y LX); lo empleó Benjumeda en la fachada del Cuartel de San Fernando (1809). El modelo de frontón semicircular, con círculo en el centro, que repitió Herrera con frecuencia en El Escorial y en la Lonja, procede del mismo libro de Serlio (lam. XXXII, XLVI y XLVII), lo empleó con más frecuencia Benjumeda en Cádiz: en la portada y alzados de la iglesia de San Pablo y en el frontal del retablo de la Virgen del Sagrario (1785-87); en la fachada de la iglesia de San José, 1787; en la fachada de la antigua Cárcel Real (1794); en la capilla sacramental de la Santa Cueva (1796); en los alzados del patio del Ayuntamiento (1816); asimismo en la fachada (1796) y decoración de los frontales de altar de la iglesia parroquial de Chiclana (1805); también en la fachada del Mercado de Puerto Real (1792-1802), así como en el proyecto de la cúpula del Cementerio (1802). Son asimismo de origen serliano/herreriano los antepechos de balaustres torneados, que Benjumeda emplea en la tribuna de los pies de la parroquia de Chiclana (1786), y en el proyecto de fachada del ayuntamiento gaditano y alzado del patio (1816). La decoración de cartelas rectangulares en fachadas procede asimismo del citado libro de Serlio (lam.LVIII), que Herrera aplica a la Lonja; Benjumeda las suele situar bajo las ventanas. Es el caso de las viviendas por piso en c/Sánchez Barcaiztegui 3 (h. 1790), que se halla modificada ${ }^{35}$; en el proyecto de fachada de la casa en c/Rosario, lindera con la iglesia de esta advocación (1793) ${ }^{36}$; en el proyecto de fachada de la c/Torre, esquina a la de la Rosa $(1795)^{37}$ y en el proyecto de fachada de una casa en la c/del Camino no 80 , propiedad de la familia Lasquetti $(1796)^{38}$, entre otras.

Otro motivo característico de este arquitecto es el de columnas y pilastras jónicas, con guirnaldas entre las volutas, que emplea tanto en la arquitectura civil, como en la religiosa, en exteriores como en interiores. Este motivo, de ascendencia italiana, lo utilizaron desde el siglo XVI al XVIII numerosos arquitectos: Carlo Maderno, Martino Longhi el Viejo, Bartolomeo Ammannati, Jacomo della Porta, Rainaldi, Borromini y Nicola Salvi, entre otros. En España tiene como antecedentes la fachada de la iglesia de Santo Tomás y San Felipe Neri de

\footnotetext{
34 Serlio, Libro $4^{\circ}$. Edición en castellano de Francisco de Villalpando en 1552.

35 JIMÉNEZ MATA y MALO DE MOLINA. Guía de Arquitectura.. op.cit., p. 222.

36 AMC. Planos. Cajón $2^{\circ}$, libro $13 \mathrm{X}$

37 Ibidem. Planos. Planos y alzados de las casas construidas en 1795. Cajón 20 11.

38 Ibidem. Planos. Planos y alzados de las casas construidas en 1796. Cajón 2ª 15. XX.
} 
Valencia (P. Tomás Vicente Tosca, h. 1736); también se halla en la decoración interior de la iglesia de la Encarnación de Madrid (Ventura Rodríguez, h. 1760); en la fachada de la capilla del antiguo Hospicio de Cádiz (Fundación Varcálcel. Torcuato Cayón, 1763) y en la Puerta de Alcalá de Madrid (Sabatini, 1778), entre otros. Entre los edificios trazados por Benjumeda figura esta decoración en los pilares de la iglesia parroquial de Chiclana (1786), así como en sus retablos (1805); en la antigua iglesia de San José de Puerto Real (desacralizada, hoy Centro Cultural San José), en los pilares y retablo mayor (1790-94). En la ciudad de Cádiz en la portada de la iglesia del Rosario (1795-96), en la de San José (1787), así como en la fachada del Ayuntamiento, 1816. Pese a la época de crisis en la que vivió Benjumeda ${ }^{39}$, que impidió la realización de grandes proyectos, tales como la monumental cúpula de la capilla del Cementerio de Cádiz, su obra edificada, como sus proyectos conservados, permiten considerarlo como el arquitecto neoclásico más importante de Andalucía.

39 A la pérdida del monopolio del comercio americano, la guerra con Inglaterra, el sitio de Cádiz por los franceses y la emancipación de las colonias americanas, hay que sumar las epidemias de peste de 1800, 1803 y 1813. Testimonio elocuente de lo que afirmamos, es la carta que envió en 1800 el párroco de la iglesia del Rosario al obispo de Cádiz. En ella manifiesta que Benjumeda ha empleado materiales más pobres de lo estipulado en el retablo mayor de este templo, así como que al recabar fondos para la construcción del templo, manifestaban algunos fieles "que era imprudencia, en un tiempo tan calamitoso, pedir para piedras, cuando no había para pan". Ms. Archivo de la iglesia parroquial del Rosario. 